\title{
НЕКТОРЫЕ ПРОБЛЕМНЫЕ АСПЕКТЫ РЕАЛИЗАЦИИ ПРИНЦИПА СПРАВЕДЛИВОСТИ В НАЛОГОВОМ ПРАВЕ РОССИИ И МЕРЫ ПО ИХ ПРЕОДОЛЕНИЮ
}

В статье отмечается актуализация проблемы справедливости в области правового регулирования налогообложения на современном этапе. Исследуются подходы, выступающие критериями конструирования справедливой системы налогообложения с позиции платежеспособности, объема получаемых от государства выгод, а также равенства правовых возможностей по защите своих прав государством и налогоплательщиком, и исследуются некоторые проблемы их практического применения.

Была выявлена неприменимость принципа выгод для построения справедливой системы налогообложения в силу исключительного многообразия налогоплательщиков по уровню получаемых доходов, по составу семьи, по возрастному, образовательному и иным критериям, что обусловливает необходимость повышенной социальной защиты определенных категорий граждан, и в данной ситуации априори невозможно следовать постулату о соответствии уплачиваемой каждым налогоплательщиком суммы полученным им общественным благам.

Был сделан вывод о том, что существующая плоская шкала налогообложения не позволяет воплощаться в объективной действительности принципу справедливости, и отмечается необходимость введения прогрессивного налогообложения в совокупности с установлением ежегодно индексируемого минимума, свободного от налогообложения.

Также исследованы такие проблемы как регрессивный характер многих налогов, ориентация налоговой нагрузки на низкодоходные категории плательщиков слабая социальная направленность и значительные масштабы уклонений от уплаты налогов.

Была критически оценена норма о бесспорном порядке взыскания с налогоплательщиков индивидуальных предпринимателей сумм налогов, пени и штрафов за нарушение законодательства о налогах и сборах, и в качестве более согласующегося с началами справедливости было предложено применение принудительного порядка взыскания доначисленных налогов, а также сумм пени и штрафа лишь после истечения установленного в законе срока обжалования налогоплательщиком акта проверки налогового органа.

Сделан вывод от оторванности существующей системы налогообложения от объективной действительности и предложены меры по внесению соответствующих изменений в законодательство России о налогах и сборах.

Ключевые слова: принцип справедливости, налогообложение, прогрессивная шкала, необлагаемый минимум, налоговые льготы, платежеспособность, налоговое администрирование.
The article notes the actualization of the problem of justice in the field of legal regulation of taxation at the present stage. The article studies the approaches that serve as criteria for the construction of a fair tax system from the perspective of solvency, the amount of benefits received from the state, as well as the equality of legal opportunities to protect their rights by the state and the taxpayer, and examines some problems of their practical application

The article shows the inapplicability of the principle benefits of a fair tax system because of the exceptional diversity of taxpayers by the level of income, family composition, age, educational and other criteria that determine the need for increased social protection of certain categories of citizens, and in this situation it is a priori impossible to follow the postulate of compliance paid by each taxpayer of the amount received public benefits.

In the analysis of solvency, the key factor was whether the amount of tax to be paid should increase in line with the growth of the person's income, which logically led to the analysis of the preference for proportional or progressive taxation.

It was concluded that the existing flat scale of taxation does not allow the principle of justice to be embodied in the objective reality, and the need to introduce progressive taxation in conjunction with the establishment of an annually indexed minimum free from taxation is noted

The author also studies such problems as the regressive nature of many taxes, the orientation of the tax burden on low-income categories of payers, weak social orientation and significant scale of tax evasion.

The article studies the norm on the indisputable procedure of collecting taxes from individual entrepreneurs, penalties and fines for violation of the legislation on taxes and fees were critically evaluated, and as a more consistent with the principles of justice, it was proposed to use a compulsory procedure for collecting additional taxes, as well as the 
amounts of penalties and fines only after the expiration of the statutory period of appeal as regards the act of inspection of the tax authority.

The conclusion is drawn concerning the isolation of the existing system of taxation from the objective reality and

Бесспорен тот факт, что принципы налогового права выступают фундаментальными началами нормативного регулирования в сфере налогообложения, способствующими органичной взаимосвязи налогового права с законодательством о налогах и сборах и налоговой политикой

Среди всего массива принципов налогового права наиболее дискуссионным и сложным является принцип справедливости.

Понятие справедливости в сфере налогообложения исключительно динамично и трансформируется сообразно социально-политическим процессам. Показательно, что еще в начале XX века С. И. Иловайский, рассматривая категорию справедливости применительно к сфере налогов и сборов, отмечал, что она весьма относительна, и то, что для одного в сорере налогов и сборов совершенно справедливо, для иного будет являться вопиющей.

По сути, справедливость выступает квинтэссенцией всех религиозных, нравственных и правовых требований. При этом указывается на то, что наибольший субъективизм принадлежит воззрениям нравственного и религиозного толка, в силу чего в вопросе о справедливости налогов в качестве руководящих начал следует воспринимать главным образом правовые начала $[1$, с. 25]

Действительно, представляется достаточно сложным, если вообще не сказать - невозможным, установление четких и более или менее стабильных критериев справедливого налогообложения, поскольку они в существенной мере зависят от исторической эпохи, в которой функционирует система налогов и сборов, от экономического устройства общества, от социального и правового статуса налогоплатепьщика и множества иных значимых фракторов. К тому же степень справедливости не может быть измерена равно как невозможно установление «эталона справедливости».

Значимость принципа справедливости не представляется возможным переоценить, поскольку справедливая система налогообложения представляет собой один из приоритетных векторов построения современного государства и общества.

В российских реалиях сегодняшнего дня запрос на социальную справедливость как никогда велик. Однако здесь уместна ссылка на слова заместителя Председателя Государственной Думы Андрея Исаева о том, что дискуссии о справедливости недопустимы в ситуации, когда оклады руководителей госкорпораций засекречены, а государство отыгрывается на государственных и муниципальных служащих, замораживая им заработную плату. При этом о состоянии дел в госкорпорациях население узнает только из the measures to make appropriate changes to the Russian legislation on taxes and fees.

Key words: principle of justice, taxation, progressive scale, non-taxable minimum, tax benefits, solvency, tax administration.

предновогодних обращений главы «Роснано» Анатолия Чубайса [2, с. 115].

Действительно, в условиях захлестнувшей Россию волны экономического кризиса, вызвавшей резкое падение уровня жизни основной части населения страны, сейчас 19,2 миллиона человек (то есть 13,1 \% населения) получает доход ниже прожиточного минимума, с неизбежностью актуализируются вопросы о социальной справедливости действующей системы перераспределения доходов и благ в обществе, находя свое значимое проявление именно в сфере налогообложения.

Вместе с тем, российская система в сфере налогов и сборов характеризуется достаточно внушительным спектром проблем, выступающих барьером для социально-экономического развития государства и общества. К их числу можно отнести, в частности, регрессивный характер многих налогов, ориентацию налоговой нагрузки на низкодоходные категории плательщиков, слабую социальную направленность и значительные масштабы уклонений от уплаты налогов Представляется, что данные факторы во многом выступили следствием несправедливости существующей системы взимания налогов и сборов.

Небезынтересно, что в литературе встречается мнение об априорной несправедливости налогообложения в силу его нацеленности на изъятие у налогоплательщика части принадлежащего ему имущества [3]. Однако хотелось бы возразить, поскольку налоговые поступления формируют материальный фундамент для исполнения государством публично-правовых функций, выполняемых в интересах, по сути, всего его населения. Поэтому представляется, что более верно вести речь не о изначально несправедливом характере налоговых обязательств, а скорее о дифференцированном понимании справедливости с позиций налогоплательщика и государства.

Подавляющий массив авторов при обосновании своих подходов к конструированию справедливой системы налогообложения исходит из двух основополагающих оснований: выгоды налогоплательщика и его платежеспособности, где первое основание предполагает состояние равновесия между «тяжестью налогового бремени» и объемом получаемых от государства общественных благ, а второе ориентирует на учет возможности налогоплательщика уплачивать налог и предполагает равенство плательщиков, находящихся на одинаковой экономической позиции.

Указанные выше подходы к принципу справедливости в налогообложении основаны исключительно на экономических интересах двух сторон налоговых правоотношений, вместе с тем, характеристика принципа справедливости не 
будет считаться полной без соблюдения важного правового аспекта, сущность которого можно определить как соблюдение в процессе налогообложения баланса прав и обязанностей государства в лице его контролирующих органов и налогоплательщиков при защите своих интересов и несении финансовой ответственности $[4$, с. 60]. Очевидно, что соблюдение указанных выше подходов на практике весьма проблематично.

Так, казалось бы, взамен уплаченных налоговых сумм налогоплательщики получают примерно равный объем государственных услуг в виде бесплатного образования, медицинского обслуживания, условий жизни и иных. Однако при более обстоятельном рассмотрении выявляется, что для практического применения данного принципа оказываемые государством услуги должны быть фактически персонифицированы, то есть иметь общественную полезность для каждого налогоплательщика. Аналогичным образом должно происходить построение системы налогообложения, когда уплачиваемая каждым налогоплательщиком сумма должна хотя бы примерно соответствовать сумме полученных им общественных благ

Реализация данного принципа на практике невозможна также в силу исключительного многообразия налогоплательщиков по уровню получаемых доходов, по составу семьи, по возрастному, образовательному и иным критериям. Так, налогоплательщики, занимающие примерно равную налоговую позицию, могут в корне отличаться друг от друга по составу семьи. И очевидно, что налогоплательщик, у которого на иждивении трое несовершеннолетних детей, будет получать от государства в три раза больше услуг в виде бесплатного образования и здравоохранения по сравнению с лицом, имеющим одного ребенка.

С другой стороны, по общему правилу, налогоплательщики пенсионного возраста имеют более низкие доходы по сравнению с лицами трудоспособного возраста, но, вместе с тем, именно пожилые люди значительно чаще прибегают к услугам государственного здравоохранения, и если следовать рассматриваемому принципу выгоды, сумма подлежащих с их стороны налогов должна быть больше. При данных обстоятельствах, в отношении этой группы населения установление соответствия между суммой уплаченных налогов и размером получаемых от общества благ невозможно, что демонстрирует неприменимость принципа выгод на практике для построения справедливой системы налогообложения [5, с. 231].

Ключевой момент при анализе фактора платежеспособности заключен в том, должна ли сумма подлежащего уплате налога увеличиваться сообразно росту уровня доходов лица. Несмотря на сложившуюся в развитых странах практику применения налогообложения по прогрессивной шкале, дискуссии о предпочтительности пропорционального либо прогрессивного налогообложения не утрачивают своей актуальности.

Хотелось бы отметить, что плоская шкала налогообложения не позволяет воплощаться в объективной действительности принципу спра- ведливости, прежде всего потому, что денежные средства, оставшиеся после уплаты налога, должны позволять налогоплательщику осуществлять жизненно необходимые расходы для него самого и для членов его семьи, связанные с питанием, проживанием, образованием, культурой и здравоохранением. В силу равенства данных затрат для всех налогоплательщиков, при условии применения плоской шкалы налогообложения удельный вес налоговых платежей в оставшейся сумме доходов низко обеспеченных слоев населения существенно превышает аналогичный у более обеспеченных граждан.

Кроме того, в качестве обоснования необходимости введения прогрессивной ставки выступает также то обстоятельство, что более состоятельный налогоплательщик испытывает большую потребность в защите частной собственности, в обеспечении целостности и неприкосновенности имущества. Отсюда, логичным и справедливым представляется внесение данной категорией налогоплательщиков в пользу государства большей доли своих доходов, что возможно лишь при введении прогрессивного налогообложения доходов физических лиц [6, с. 108]

Если объективно оценить современные российские реалии, то приходится констатировать ярко выраженный регрессивный характер налогообложения доходов, поскольку у лиц с высоким уровнем дохода на уплату налогов приходится гораздо меньшая их доля, и, соответственно, у менее обеспеченных слоев населения более высокая доля уплачиваемых налогов в общей сумме их доходов. Усугубляет ситуацию также отсутствие в российской системе налогообложения не облагаемого налогом минимального дохода, и в качестве плательщиков НДФЛ выступает практически все трудоспособное население страны, уровень доходов которых нередко не достигает прожиточного минимума

Напротив, если проанализировать иные налоги, взимаемые с физических лиц, к примеру, налог на имущество, следует указать на тот факт, что налоговая ставка может варьироваться от 0,1 до $2 \%$ от кадастровой стоимости недвижимого имущества, где используется простая прогрессия, при которой размер ставки прямо пропорционален стоимости объекта налогообложения, что приводит к логичной мысли о нацеленности законодателя на возложение большего налогового бремени на состоятельную часть населения. Аналогичный критерий положен в основу правовой конструкции транспортного налога, ставка которого производна от мощности двигателя. В дополнение с 2014 г. были введены повышающие коэфффициенты к ставкам налога на престижные автомобили стоимостью 3-5 млн рублей не старше 3 лет, в 2018 г. ставший единым - 1,1 [11].

Из вышеизложенного достаточно очевидна тенденция усиления прогрессивных начал в налоговой политике государства по отношению к налогообложению имущества. Однако важно отметить тот факт, что собственник дорогой недвижимости совсем не обязательно получает 
высокий доход на регулярной основе, поскольку он мог получить элитное жилье, престижный автомобиль либо земельный участок по наследству либо иным основаниям. Даже если имущество приобретено на собственные доходы - лицо могло лишиться постоянного дохода в значительном размере. При подобных обстоятельствах налогоплательщики, обладая одинаковым доходом, но различным по стоимости имуществом должны отчуждать в пользу государства в корне отличные друг от друга суммы налога.

Таким образом, уместен вывод о том, что лишь размер получаемого налогоплательщиком регулярного дохода выступает показателем его платежеспособности, в силу чего прогрессивный характер налогообложения имущества в совокупности с регрессивной направленностью налогообложения доходов физических лиц нельзя признать в полной мере согласующимся с соблюдением принципа справедливости [8, с. 326].

Пытаясь ответить на вопрос о причинах сложившейся ситуации, можно предположить, что она связана с опасением роста случаев укрывательства состоятельной части населения от налогообложения в случае введения прогрессивной шкалы. Поэтому, учитывая крайне непропорциональное соотношение в уровне доходов населения России, государство в качестве инструмента экономического перераспределения избрало усиление налоговой нагрузки на имущество граждан, гораздо более проблематичное для сокрытия от налогообложения.

Аналогичная тенденция прослеживается применительно к налогу на прибыль, и в связи с этим не лишены рационального начала предложения о введении (изначально на уровне ряда регионов в качестве некого «пилотного проекта») регрессивных ставок налога на прибыль, понижение которых обусловлено увеличением суммы налогооблагаемой прибыли. В этом случае понижающая прогрессия ставок будет влечь не стремление скрыть налогооблагаемую базу, а показать ее в полном объеме, поскольку с увеличением суммы полученной прибыли ставка налога будет уменьшаться. И в данной ситуации были бы безосновательными опасения о сокращении бюджетных поступлений, поскольку их сумма определяется не столько ставкой, сколько величиной налогооблагаемой базы, которая рассматриваемом случае имела бы тенденцию к росту.

Далее, рассмотрение правового подхода к принципу справедливости в российской системе налогообложения также иллюстративно «обнажает» некоторые проблемные аспекты. К примеру, не представляется возможным в полной мере разделить тезис о равенстве возможностей налогоплательщиков при защите своих интересов.

На сегодняшний день отсутствует какая-либо диффференциация ответственности за злостное уклонение от уплаты налогов и неумышленные нарушения в данной сфере, что является весьма существенным упущением законодателя, и в целях укрепления принципа справедливости представляется целесообразным обусловить уровень финансовой ответственности налогоплательщика степенью его вины в совершении налогового правонарушения.

Также сомнительна справедливость предусмотренного в налоговом законодательстве бесспорного порядка взыскания с налогоплательщиков индивидуальных предпринимателей сумм налогов, пени и штрасов за нарушение законодательства о налогах и сборах, поскольку, даже в случае признания их неправомерными иными судебными инстанциями, последствия экономического и репутационного характера останутся.

Более соответствующим началу справедливости было бы применение принудительного порядка взыскания доначисленных налогов, а также сумм пени и штрафа лишь после истечения установленного в законе срока обжалования налогоплательщиком акта проверки налогового органа.

Между тем, на практике налоговые органы зачастую игнорируют регламентированный ст. 69 НК РФ минимальный 8-дневный срок для добровольного исполнения налоговой обязанности, который должен указываться в направляемом требовании об уплате налога, и начинают процедуру бесспорного взыскания до его истечения, что нельзя признать допустимым.

Не могут также не вызывать скептицизм в аспекте согласованности с принципом справедливости правила, фактически закрепляющие право на «законотворчество» Минфина и финансовых органов, которые свободны в трактовке положений НК РФ, и изданные ими нормативные акты императивны для соблюдения налогоплательщиками. Данное обстоятельство лишь усиливает дисбаланс в правовом положении налогоплательщиков и контролирующих органов.

Безусловно, в рамках настоящей статьи не представляется возможным охватить весь спектр острых проблем в сфере воплощения принципа справедливости в налоговом праве России. Так, требуют также своего разрешения вопросы недостаточной адресности налоговых льгот, массовости уклонения от уплаты налогов, что позволяет налогоплательщикам избежать либо уменьшить в той или иной степени его обязательные выплаты в бюджет и внебюджетные фонды, а также множество иных [9, с. 317]

При этом в отношении уклонения от налогов как фактора, деструктивно отражающегося на справедливости системы налогообложения, следует отметить, что существующая ситуация в сфере взимания налогов и сборов предоставляет налогоплательщикам массу «лазеек» для уклонения от уплаты налогов

Помимо этого, на сегодняшний день также отсутствуют четкие и эффективные механизмы нивелирования данных негативных последствий, в силу чего на государственном уровне требуют своего незамедлительного решения данные проблемы для создания справедливой налоговой системы с целью реального снижения налогового бремени для законопослушных налогоплательщиков и предотвращения бюджетных потерь за счет уклонения от уплаты налоговых платежей. 
В аспекте реализации принципа справедливости следует также указать, что отрицательные последствия уклонения от уплаты налогов весьма пагубны как для экономики, так и для государства в целом. Государственный бюджет в силу недополучения причитающихся ему средств вынужден ограничивать реализацию ряда значимых государственных программ, выплату заработной платы работникам бюджетной сферы и т.д.

Как видится, одна из базисных причин уклонения от уплаты налогов как массового явления несправедливо завышенные налоговые ставки при стабильно низком уровне жизни подавляющего большинства населения России, а также ухудшение финансового положения и платежеспособности предприятий [10, с. 266].

В целом, резюмируя вышеизложенное, приходится констатировать достаточно слабое соблюдение принципа справедливости в налоговом праве России на современном этапе, что требует принятия соответствующих мер нормотворческого, финансово-экономического и организационного характера.

Среди них, как видится, одной из приоритетных выступает обстоятельная разработка и введение продуманной прогрессивной шкалы налогообложения в совокупности с установлением минимума, свободного от налогообложения, соответствующего величине прожиточного минимума и подлежащего ежегодной индексации в соответствии с уровнем инфляции. Представляется, что это создаст надежный фундамент для воплощения начал справедливости в налогообложении, а также выступит пусковым механизмом реализации регулирующей и социальной функции налогов.

Кроме того, как верно отметил Министр финансов РФ А. Г. Силуанов, важно осуществить перестройку мер налоговой поддержки, поскольку подавляющее число налоговых преференций, вопреки представлениям о справедливости, получают лица с высоким уровнем дохода. Необходимо внедрение критерия адресности данной помощи, что начало проявлять себя на примере предоставления материнского капитала [6].

Как видится, Минфин также нацелен на отказ от ряда налоговых льгот, которые предусмотрены для всех потребителей (к примеру, реализация ряда товаров (детские, продовольственные, медицинские) подпадает под 10 \% льготную ставку НДС вместо общей $18 \%$ в в целях направления дополнительно аккумулируемых налогов на целевую поддержку нуждающихся, что следует воспринять как достаточно прогрессивную идею, поскольку в 2017 г. цена пониженной ставки НДС по этим категориям товаров для федерального бюджета составила 528 млрд руб.

Также в аспекте реализации принципа справедливости в сфере налогообложения вполне уместна идея о необходимости акцентирования внимания на администрировании налоговых поступлений, и, в особенности, НДФЛ и страховых взносов путем контроля за соответствием между декларируемым доходом фризических лиц, уплаченным ими налогом на доходы фризических лиц и понесенными расходами.

Следует отметить, что уже на современном этапе возможности электронного контроля посредством внедрения онлайн-касс за банковскими счетами граждан, а также над совершаемыми ими покупками позволяют налоговым органам сопоставить задекларированные доходы с оборотами по счетам и понесенным расходам.

Однако это не следует воспринимать радикально, будто сумма подлежащих уплате налогов будет исчисляться в автоматическом режиме исходя из суммы потраченных средств. Но, безусловно, эти данные могут послужить основанием для проверки, поскольку налоговые органы могут выявить факты неуплаты работодателем страховых взносов либо обнаружить схемы с серыми зарплатами

К сожалению, вместо указанных эффективных мер в настоящее время наблюдаются попытки выхода из кризиса и пополнения бюджета за счет наименее социально защищенных групп населения путем немотивированного увеличения налога на имущество физических лиц, введения курортного сбора как слепого следования западным порядкам без учета специфики российских реалий, чрезмерное распространение налоговых льгот в отрыве от критерия адресности, слабый контроль за сбором налогов, приводящий к уклонению от уплаты налогов и многие иные факторы, оказывающие деструктивное влияние на сферу налогообложения.

В 2018 г. подойдет к своему завершению введенный в 2014 г. мораторий на изменения в налоговой сорере, и уже отмечается кропотливая работа правительства, экспертов и бизнес-сообществ по подготовке соответствующих мер по обеспечению устойчивости системы налогов и сборов а также нивелированию ее абстрагированности от объективной реальности и базисных принципов налогообложения, прежде всего, принципа справедливости.

\section{Литература}

1. Антонова Е. А. Недостатки современной налоговой системы // Молодой ученый. 2017. №14. С. 316-318.

2. Глоян Р. Р., Мартиросян А. А., Кусиди А. Н. Реализация принципа справедливости в российском налоговом праве // Управление и экономика в XXI веке. 2015. №2. С. 25.

3. Демин А. В. Право, справедливость, налогообложение: исходные предпосылки URL: https://www.lawmix.ru/ comm/5656 (Дата обращения: 8.04.18)

4. Куксин И. Н., Чечельницкий И. В., Липунов В. И. Принцип справедливости как критерий оценки современного налогового законодательства России // Научные ведомости Белгородского государственного университета. 2016. №10 Выпуск 36. С. 114-119. 
5. Майбуров И. А., Соколовская А. М. Теория налогообложения. Продвинутый курс: учебник для магистрантов. М.: Юнити-дана, 2011. 591 с.

6. Минфин рассказал о целях изменения налоговой системы URL: http://bhnews.ru/minfin-rasskazal-o-tselyahizmeneniya-nalogovoj-sistemy (Дата обращения: 2.05.18).

7. Налоговое право: учебник / под ред. С. Г. Пепеляева. М.: Альпина Паблишер, 2015. 800 с.

8. Пансков В. Г. Принцип справедливости и его отражение при налогообложении физических лиц в российской налоговой системе // ЭТАП: экономическая теория, анализ, практика. 2016. С. 58-71.

9. Пансков В. Г. Прогрессивная или пропорциональная шкала налогообложения: что справедливее и эффективнее? // Экономика. Налоги. Право. 2017. №2. С. 105-112.

10. Сивцева В. И. Проблема массового уклонения от уплаты налогов // Молодой ученый. 2017. №10. С. 266-268

11. Федеральный закон «О внесении изменений в статью 362 части второй Налогового кодекса Российской Федерации» от 23.07.2013 № 214-Ф3 // СПС «КонсультантПлюс») URL: http://www.consultant.ru/ doc_LAW_149660/ (Дата обращения: 5.05.18).

\section{References}

1. Antonova E. A. Nedoststatky sovremennoi nalogovoi sistemy (Shortcomings of the Modern Tax System) // Young scientist. 2017. No.14. P. 316-318. (In Russian).

2. Demin A. V., Pravo, spravedlivost, nalogooblozheniye: ishodniye predposilky (Law, Justice, Taxation: Presuppositions) URL: https://www.lawmix.ru/comm/5656 (Accessed: 08.04.18). (In Russian).

3. Gloyan R. R., Martirosyan A. A., Kusidi A. N. Realizatsiya printcipa spravedlivosty $\vee$ rossiiskom nalogovom prave (Implementation of the Principle of justice in Russian tax law) // Management and economy in the XXI century. 2015. No. 2. P. 25. (In Russian).

4. Kuksin I. N., Chechelnitsky I. V., Lipunov V. I. Princip spravedlivosty kak kritery otcenky sovremennogo nalogovogo zakonodatelstva Rossii (The principle of Justice as a Criterion for Assessing the Modern Tax Legis/ation of Russia) // Scientific statements of Belgorod state University. 2016. №10. Issue 36. P. 114-119. (In Russian).

5. Mayburov I. A., Sokolovsky A. M. Teoriya nalogooblozheniya Kurs dlya prodvinytih: ychebnik dlya magistrantov (The Theory of Taxation. Advanced Course: Textbook for Undergraduates). Moscow: YUNITI-DANA, 2011. 591 p. (In Russian).

6. Ministr finansov rasskazal o tselyah izmeneniya nalogovoi systemy (The Ministry of Finance Has Told about the Purposes of Changes in the Tax System) URL: http://bhnews.ru/minfin-rasskazal-o-tselyah-izmeneniya-nalogovoj-sistemy (Accessed: 02.05.18). (In Russian).

7. Nalogovoe pravo (Tax Law): the Textbook. Moscow: Alpina Publisher, 2015. 800 p. (In Russian).

8. Panskov V. G. Princip spravedlivosty I ego otrazheniye pri nalogooblozhenii fizicheskih lic v rossiiskoi nalogovoi sisteme (Principle of Justice and its Reflection in the Taxation of Physical Persons in the Russian Tax System) // Stage: economic theory, analysis, practice. 2016. P. 58-71. (In Russian).

9. Panskov V. G. Progressivnaya ili proportcionalnaya shkala nalogooblozheniya: chto chestnee I bole effectivno (Progressive or Proportional Scale of Taxation: What is Fairer and More Effective?) // Economy. Tallage. Right. 2017. No. 2. P. 105-112. (In Russian).

10. Sivtceva V. I. Problema massovogo ukloneniya ot uplaty nalogov (The Problem of Mass Tax Evasion) // Young scientist. 2017. No. 10. P. 266-268. (In Russian).

11. Federalnyj zakon O vnesenii izmenenij v statyu 362 chasti vtoroj Nalogovogo kodeksa Rossijskoj Federacii ot 2307 2013 214-FZ (The Federal Law "On Amendments to Article 362 of Part Two of the Tax Code of the Russian Federation" Dated 23.07.2013 № 214-FZ) // ATP «ConsultantPlus» [Electronic resource] URL: http://www.consultant.ru / doc_LAW_149660 / (Accessed: 5.05.18). (In Russian). 